\title{
El análisis: ¿un género periodístico?
}

\author{
Dr. Antonio López Hidalgo \\ Periodista y profesor titular de Redacción Periodística \\ en la Facultad de Comunicación de la Universidad de Sevilla
}

\section{RESUMEN}

Desde hace ya algunos años los medios de comunicación escritos han generalizado la modalidad de presentar textos de análisis desgajados de los elementos previos que debieran figurar en un texto informativo-interpretativo completo o en un texto interpretativo-opinativo. Es decir, estos textos de análisis se presentan como géneros periodísticos autónomos e independientes, lejos de aquellos otros textos a los que debieran complementar. Hasta ahora el análisis sólo era una técnica interpretativa que encontraba su piedra angular en los datos antecedentes. En este viaje en solitario es donde este nuevo género periodístico debe encontrar su propia entidad, más allá de aquellos ángulos opinativos que en ocasiones le privan de una personalidad propia $y$ le aproximan al comentario.

\section{ABSTRACT}

Since several years ago printed Media Communication have generalizad the trend of editing análisis text without previous elements, which must figure in a complete informativeinterpretative text or an interpretative-opinion text. That is to say these analysis texts are showed like autonomous and independent journalistic genres, separated and distinguished from those other texts that should be ompleted for them. Until now the analysis was only considered like an interpretative technique based on background. This new journalistic genre must find its own identity along this way in solitarie, beyond those opinion sketches and parameters which sometimes stripped them of its genuine personality and make them similar to journalistic comment.

Palabras claves: Periodismo interpretativo/Géneros periodísticos complementarios/Técnica sidebar/Comentario/Análisis.

Key words: Interpretative journalism/Complementary journalistic genres/'Sidebar" technique/ Journalistic comment/Análisis.

\section{Introducción}

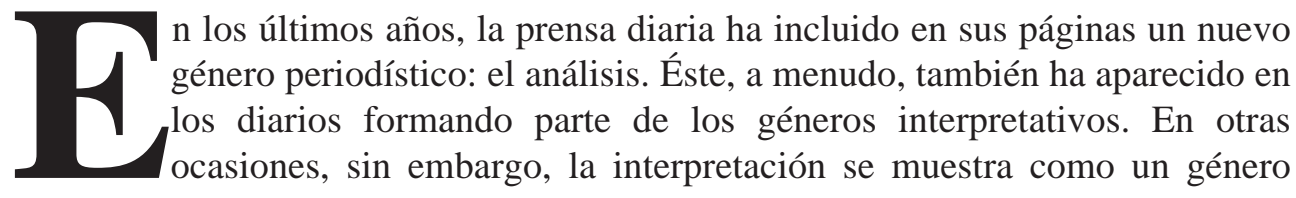


El análisis: ¿un género periodístico?

donde el enfoque sustancial parte de elementos de opinión, y en el que la pura información queda en un segundo plano. Distintos autores ya han alzado la voz en este sentido.

Luisa Santamaría, por ejemplo, ya ha advertido sobre este aspecto: «Se está generalizando en los medios de comunicación la modalidad de presentar textos de análisis desgajados de los elementos previos que debieran figurar en un reportaje interpretativo completo. Estos textos analíticos tienen muchos puntos de contacto con los textos de opinión llamados comentarios, y suelen aparecer firmados por un columnista de prestigio profesional» ${ }^{1}$.

En cualquier caso, el análisis, ya forme parte del cuerpo informativo de otro género periodístico, o ya se presente de manera aislada, como si fuese un texto autónomo, debe hundir sus raíces en la interpretación, en la posibilidad de ofrecer una lectura contextualizada y explicada de los hechos a los que hace referencia. Para cumplir esta función, debe encontrar en el background el material suficiente para su elaboración y excluir, a toda costa, los juicios de valor. En esa línea, a veces imperceptible, se encuentra su naturaleza y su razón de ser. Desde luego, no siempre es fácil elaborar un texto de análisis más allá de la información sin poder rehuir de la opinión. Sobre esa cuerda se desliza y tambalea la difícil tarea del analista de la actualidad.

\section{El background, infraestructura del análisis}

Para Concha Fagoaga, un elemento básico del mensaje interpretativo es el background o datos antecedentes, que permite relacionar el pasado con el presente. En la interpretación siempre existe la referencia a una situación específica marcada por unos hechos de actualidad que son los que se analizan y valoran. Sheeham ${ }^{2}$ diferencia estos datos: en los mensajes directos, las citas son frescas, de producción reciente; en los mensajes interpretativos, proceden en buena parte de relatos pasados y sirven con justeza para adecuar la situación de fondo.

Algunos autores, como Charnley ${ }^{3}$, definen el background como «todo material subyacente o circunstancial relacionado con el hecho que origina la noticia». Este autor señala que el background debe presentarse objetivamente; su único propósito es ayudar al receptor a situar el acontecimiento en el debido contexto; y éste no evalúa el significado de las noticias, pero le da elementos al lector para que él mismo haga la evaluación.

1 SANTAMARÍA, Luisa: "Géneros periodísticos de opinión”, en BENITO, Ángel (dir.): Diccionario de Ciencias y Técnicas de la Comunicación, Ediciones Paulinas, Madrid, 1991, p. 636.

2 SHEEHAM, Paul V.: Periodismo interpretativo, Troquel, Buenos Aires, 1971, p. 292.

3 CHARNLEY, Michell V.: Periodismo interpretativo. Troquel, Buenos Aires, 1971, p. 435. 
Fagoaga señala que el propósito del background es sumar información. El tratamiento se lleva a cabo conforme al «relato objetivo de los hechos». No hay interpretación. Los hechos desnudos no explican nada. El background en los mensajes interpretativos es la infraestructura, el fundamento que sirve de referente para analizar y estimar resultados. En definitiva, poner en situación el pasado con el presente es lo que va a servir de eje del trabajo. Elaborar un relato background es, por lo tanto, bastante más simple que trabajar con técnicas interpretativas, añade Fagoaga.

Mencher $^{4}$, al mencionar el background como elemento de apoyo al mensaje interpretativo, como el referente para analizar y estimar datos, señala estas acepciones:

a) La información que se almacena a largo plazo. Poseer un buen conocimiento del entorno donde los hechos se produzcan es requisito indispensable para poder ofrecer una interpretación sobre ellos. Ésta es una de las razones por la que los periodistas acaban especializándose en un área de contenidos que los legitima como expertos. Hohenberg ${ }^{5}$ llega a afirmar que el status del periodista no se consolida hasta que éste adquiere especialización, lo que equivale a decir que no se consolida mientras no posea un background de largo alcance.

En este sentido, Grijelmo puntualiza que para escribir un análisis se precisa competencia en la materia, experiencia en el tema del que se hable; en definitiva, antecedentes que tiene archivados en su memoria el propio periodista ${ }^{6}$.

b) La información que se almacena para cubrir un determinado relato. En la investigación, previa a la puesta en forma del mensaje, se almacenan múltiples datos, la mayoría de ellos publicados, pero de una forma dispersa, aislados entre sí. Este material es tan necesario en los mensajes informativos como en los interpretativos.

También Grijelmo hace mención a que se puede acudir a los antecedentes de documentación, pero en ese caso el texto perderá viveza y se notará acartonado: «El análisis debe nacer de la propia reflexión del autor, y ésta ha de sobrevenir antes de la iniciativa de escribir». No obstante, advierte que ello no obsta para que la reflexión que nos mueva a abordar un análisis se quede desnuda de datos y otros antecedentes ${ }^{7}$.

4 MENCHER, Melvin: News Resporting and Writing, Wm. Cm. Brown, Dubuque, Iowa, 1979, p. 205.

5 HOHENBERG, John: Los medios informativos, Letras, México, 1970, p. 333.

6 GRIJELMO, Álex: El estilo del periodista, Taurus, Madrid, 1997, p. 118.

7 Ibídem, p. 118. 
c) El uso del background, como elemento materializado en el cuerpo del relato, no está confinado en un solo párrafo. Al contrario, éste aparece en el relato en el orden lógico que sirva para apoyar datos de análisis y estimación. Puede darse background al comienzo, en medio y al final del relato siempre en apoyo de los otros elementos.

d) Background de fuente no atribuible. Son datos, análisis y valoraciones que proceden de una fuente conocida por el periodista, pero a la que no puede atribuirse ninguna cita que ponga esta fuente al descubierto. El que este material pueda ser difundido o no depende de las instrucciones de la fuente informativa.

\section{Las técnicas interpretativas no son géneros periodísticos}

Pero los mensajes interpretativos no son géneros periodísticos autónomos, sino que se muestran como técnicas periodísticas que sirven de apoyo y complemento a otros géneros periodísticos, piezas imprescindibles en sus estructuras para no mostrar los hechos aislados, sino explicados en su propio contexto. En este sentido, Concha Fagoaga es contundente: «Cabe volver ahora a la propuesta inicial de considerar a los mensajes interpretativos simplemente como mensajes informativos dotados de cuantos elementos explicativos sean indispensables para aportar al receptor una valoración sobre hechos de actualidad. El hecho de volver a incidir sobre esta propuesta de definición es para considerar que las técnicas interpretativas en sí mismas no forman géneros periodísticos. Estas técnicas se adecuan al reportaje y a la crónica, tradicionalmente conceptuados como géneros informativos, transforman el relato objetivo de hechos en relato interpretativo y toman los rasgos de presentación de la columna de opinión para establecer columnas interpretación de noticias. De forma que las crónicas pueden ser simplemente estructuradas como relato objetivo de los hechos o como crónica interpretativa. Igualmente ocurre con el reportaje. En cuanto a la columna, puede tomar todas las apariencias formales de la columna propia de comentaristas de opinión y ser estructurada como una columna interpretativa $»^{8}$.

Todavía más, podría afirmarse que las técnicas interpretativas se aplican de hecho ya a todos los géneros periodísticos, tanto informativos como de opinión. En el primero de los casos, se les aplica sólo el análisis; en el segundo, análisis y valoración.

Pero a veces y cada vez más, como decíamos al comienzo, el análisis se muestra en los diarios desgajado del texto informativo del que debía estar formando parte, de manera que aparece como un complemento o incluso como una parte autónoma respecto del género anterior.

8 FAGOAGA, Concha: Periodismo interpretativo. El análisis de la noticia, Editorial Mitre, Barcelona, 1982, p. 103. 
Concha Fagoaga también se ha referido a este aspecto. En este sentido, afirma que los mensajes interpretativos pueden encontrarse en cualquier sección del diario, pues no se hallan confinados en un determinado espacio o página, y que a veces se les aplica la técnica sidebar, que consiste en presentarlos como un relato complementario al lado del relato informativo directo, aunque también se utiliza como simple background o relato de antecedentes, es decir, como si fuese un complemento.

Hohenberg ${ }^{9}$, sin embargo, aconseja que la condición interpretativa del relato debe quedar indicada en el título del relato complementario, de manera que el receptor pueda orientarse para saber que ese relato es sobre todo una explicación. En este sentido, el diario internacional International Herald Tribune suele utilizar el significante visual New Analysis para diferenciar los mensajes interpretativos de los informativos directos. Pero el diario norteamericano utiliza esta señal para relatos principales. En España, el epígrafe 'Análisis' se encontraba hasta hace bien poco sólo encabezando relatos interpretativos complementarios. Desde hace unos años, no obstante, los análisis, igual que en este diario norteamericano, se visualizan en los diarios como textos principales, como géneros autónomos, no sólo desgajados del relato informativo, sino que se muestran sin la presencia en la página de estos relatos. Es aquí donde el análisis adopta características propias como género periodístico.

Concha Fagoaga también menciona esta dualidad: «Se puede decir entonces que los mensajes interpretativos aparecen fundamentalmente en crónicas de corresponsales, en reportajes, en columnas de periodicidad fija (generalmente diaria o semanal) y también como simple relato de hechos al que se incorpora análisis y valoración, o al menos, el primero de estos dos elementos» ${ }^{10}$.

\section{El análisis, producto de la técnica sidebar}

Desde hace unos años, el periodismo ha ido evolucionando con la pretensión de ser más visual, más fácil de leer, de llegar al lector con más facilidad. El periodismo ha buscado un diseño cada vez más atractivo, una tipografía legible y estética, fotografías e imágenes que hagan más digeribles las páginas, el color como un recurso útil y atractivo. Se han multiplicado los elementos de la titulación que faciliten la lectura en doble velocidad. Y se han troceado los textos para hacerlos más breves y legibles. Es decir, se ha ofrecido la información fragmentada. De manera que un texto principal aparecía en la página complementado con otros textos que estaban subordinados al primero desde un punto de vista temático,

9 HOHENBERG, John: The professional journalist, New York, 40 edición, 1978, p. 439.

10 FAGOAGA, Concha: Op. cit., p. 103. 
El análisis: ¿un género periodístico?

si bien desde la perspectiva de su estructura interna eran autónomos. En ocasiones, estos textos complementarios contenían datos de actualidad, en otros información documental, o bien ofrecían anécdotas, hechos ya interpretados u otras noticias relacionadas con el texto principal.

A estos textos se les ha denominado indistintamente despieces, apoyos, complementos, noticias complementarias, recuadros de apoyo, etcétera. A veces, adquieren la estructura de los géneros tradicionales, otras optan por los recursos propios de determinados elementos de la titulación, otras por estructuras simples que son nada más que relaciones de datos, como es el caso de la biografía, bibliografía o cronología. A veces también muestran una libertad total en su estructura interna. Pueden ser informativos, documentales, interpretativos, argumentativos, creativos, o un poco de todo. A este conjunto de textos que dependen de una información principal los he denominado géneros periodísticos complementarios y los he estudiado a fondo en un libro de reciente aparición ${ }^{11}$.

El contenido de estos textos complementarios puede estar basado en datos de actualidad, pero también puede estar redactado solamente con datos de documentación. Esta documentación -datos de antecedentes y datos de contexto- eran la base, como se ha explicado, para elaborar el periodismo de interpretación, la pieza fundamental que nos servía para contextualizar, explicar y analizar los hechos, el cordón umbilical que nos enlazaba el pasado con el presente y que posiblemente nos podía permitir adivinar o esgrimir el futuro.

Muchas informaciones principales se nos ofrecen ahora troceadas y descontextualizadas. El resultado es deducible: el contenido de estos textos periodísticos centrales cada día es más informativo, a diferencia de muchos complementos que se tornan más interpretativos o creativos, aunque ciertamente también pueden ser informativos o sencillamente relaciones de hechos y fechas, datos y cifras. Como consecuencia, sobre todo en los diarios de ámbito provincial, los géneros informativo-interpretativos cada día son menos usuales, pues la interpretación se incluye en un texto complementario.

Algunos géneros complementarios podemos etiquetarlos como géneros periodísticos, porque tienen su propia estructura interna, y otros como subgéneros, en tanto que su estructura interna es muy simple, como es el caso de las cronologías, de las bibliografías o de algunos textos de información útil propios del periodismo de servicio. Pero estos géneros periodísticos, en ocasiones, están compuestos de texto y gráficos o fotografías. Podemos considerar géneros periodísticos complementarios a la fotonoticia y a la infografía y subgéneros al infograma y a los distintos gráficos informativos.

11 LÓPEZ HIDALGO, Antonio: Géneros periodísticos complementarios. Una aproximación crítica a los formatos del periodismo visual, Comunicación Social Ediciones y Publicaciones, Sevilla, 2002. 
El análisis periodístico surgió precisamente de esta necesidad de trocear los textos y de ofrecer al lector, en piezas separadas, la información y la interpretación. Es decir, al mensaje interpretativo se le aplicaba la técnica sidebar, que consistía en presentarlo como un relato complementario al lado del relato informativo directo, aunque también se utiliza como un simple relato de antecedentes. Este relato complementario se situaba junto al texto informativo principal encabezado con el epígrafe "Análisis".

Pero desde hace ya algunos años los medios de comunicación han generalizando la modalidad de presentar textos de análisis desgajados de los elementos previos que debieran figurar en un reportaje interpretativo completo. Es decir, muestran estos textos de análisis como géneros autónomos e independientes, lejos de aquellos géneros informativos a los que debieran complementar. En este viaje en solitario es donde este nuevo género periodístico debe encontrar su propia entidad, más allá de aquellos ángulos opinativos que en ocasiones le privan de una personalidad propia.

Ya decíamos que Santamaría hacía referencia a este hecho nuevo de que se estaba generalizando la modalidad de presentar textos de análisis desgajados de aquellos otros elementos que debieran figurar en un reportaje interpretativo. No ha sido la única advertencia. También Martínez Albertos ha alzado la voz en este sentido. El profesor emérito de la Universidad Complutense señala que el análisis corresponde a las funciones propias de la interpretación periodística, mientras que el comentario debe quedar reservado meticulosamente a la reducida parcela de la opinión. Para este profesor, el relato interpretativo completo es la suma de cuatro ingredientes: acontecimiento principal, antecedentes y circunstancias actuales, reacciones e interpretaciones. Sin embargo, ha advertido también, como ya hemos señalado, que en la práctica habitual del periodismo interpretativo se está generalizando la moda de presentar textos de análisis desgajados de los tres ingredientes previos que debieran figurar en un reportaje interpretativo completo. Y concluye: "Estos textos analíticos brindan muchos puntos de contacto con los textos de opinión llamados comentarios, y suelen aparecer firmados por un columnista de prestigio profesional" 12 .

También David Randall puntualiza que toda crónica de algún peso debe incluir una parte de análisis, ya sea entretejida con la narración o en una sección aparte, pero que muchas veces una información posee tal envergadura o adquiere tanta importancia que se le dedica un texto exclusivamente dedicado a analizarla. En este sentido, añade que los análisis diseccionan los sucesos, temas, asuntos o procesos en un intento de explicar qué está sucediendo o qué sucederá en el futuro y que al mismo tiempo deben tratar de explicar la importancia de los hechos y su

12 MARTínEZ ALBERTOS, José Luis: El ocaso del periodismo, CIMS, Barcelona, 1997, pp. 205-206. 
El análisis: ¿un género periodístico?

contexto. Y es contundente: "Estos textos no deben ser un encadenamiento de afirmaciones. Ni tampoco un refrito de informaciones antiguas aderezado con algunas opiniones. Deben presentar datos e interpretaciones sobre la información. Éstas últimas pueden ser las del propio periodista o, preferentemente, de autoridades y expertos cuyos nombres se faciliten. Se hará hincapié en la interpretación y la explicación"13.

En consecuencia, tanto Santamaría, Fagoaga, Martínez Albertos como Randall advierten de esa realidad que ya nosotros hemos constatado: que los textos informativo-interpretativos se trocean ofreciendo de un lado la información de actualidad y de otro el análisis interpretativo, y que incluso en los últimos años estos textos de análisis se publican independientemente del relato informativo. Es en este caso cuando podemos hablar del análisis como género periodístico autónomo, que en muchas ocasiones guarda muchos puntos en común con los géneros de opinión, sobre todo con el comentario.

Ahí es donde radica, en realidad, el límite de su frontera y la posibilidad de que pueda sobrevivir a los juicios de valor sin menoscabo de perder identidad. El libro de estilo de El Mundo también se detiene en este punto. El mismo señala que el análisis es un género aparentemente a caballo entre la información y la opinión, aunque debería quedar adscrito a la primera de estas dos categorías. En efecto, recuerda que el género aporta datos complementarios y elementos de reflexión que pueden ayudar al lector a formarse un juicio sobre una noticia específica o sobre una situación, pero que el hecho de aportar elementos para "formarse una opinión no es sinónimo de dar opinión".

Este manual, no obstante, quiere ser explícito en este sentido: "Un análisis no es ni una columna en la que su autor expresa su opinión ni un editorial en el que la expresa el propio periódico. Hay intencionalidad, sin duda, en la selección de datos y en su presentación. Pero el análisis debe tan sólo permitir al lector comprender los antecedentes, el sentido y la perspectiva de la noticia. El redactor se abstendrá de incluir juicios de valor y vigilará con particular atención el uso de adjetivos" 14 . Pero el mismo manual insiste en que es infrecuente en el periodismo español que estas condiciones se cumplan y que al final se presentan como análisis lo que son columnas de opinión "apenas disfrazadas".

También Luisa Santamaría sostiene que a veces el análisis contiene demasiada opinión: "El fundamental punto de contacto se da cuando el análisis se basa en razones probatorias de carácter persuasivo para sustentar una tesis. En este caso, el análisis es prácticamente un artículo de opinión”. En este sentido, Santamaría recuerda la definición que de analista y comentarista contenía el manual de

13 RANDALL, David: El periodista universal, Siglo Veintiuno de España Editores, Madrid, 1999, pp. 204205.

14 El Mundo. Libro de estilo, Ediciones Temas de Hoy, Madrid, 1966, p. 25. 
la agencia Efe en su edición de 1989: "Analista: En el trabajo periodístico, persona que escribe el análisis o explicación objetiva de los hechos noticiosos, y que aporta los datos precisos para interpretarlos correctamente. No debe usarse en lugar de comentarista". "Comentarista: En el trabajo periodístico, persona que enjuicia subjetivamente los acontecimientos y que manifiesta de manera explícita su opinión. No debe confundirse con analista".

Pero no siempre el análisis, basado en la exposición objetiva de los hechos, y el comentario, enjuiciamiento subjetivo que se lleva a cabo mediante la argumentación, aparecen ciertamente delimitados en la prensa. También Grijelmo advierte sobre este riesgo: "Así como el cronista puede caer, sin proponérselo, en el género contiguo que es el análisis, al analista le puede tentar, igualmente sin querer, el estilo cercano al editorial (el paso siguiente en los grados de opinión)". En este sentido, puntualiza que el analista explica lo que alguien ha hecho y razona el porqué; el editorialista dice qué debería hacerse o haberse hecho. El analista debe mostrarse desapasionado; el editorialista puede apasionarse tanto como el estilo de su periódico lo permita"15.

Como criterio diferenciador entre el análisis y el comentario, Martínez Albertos propone el siguiente método útil para el contraste rápido del producto sometido a examen: "Si el texto se desarrolla dentro de las normas de la Retórica clásica acerca de la exposición de los hechos y de las ideas, apoyándose en razones probatorias objetivas, entonces tendremos un análisis interpretativo; si el texto desarrollado en la línea de la argumentación, con razones probatorias de carácter persuasivo y puntos de vista evidentemente personales, estaremos ante un caso de columna de opinión, o verdadero comentario periodístico equiparable a un editorial aunque lleve la firma del autor"16.

El método de trabajo en el tratamiento del mensaje interpretativo se lleva a cabo por medio del análisis y la valoración. Según Paul White ${ }^{17}$, que fue director de programas informativos de la CBS, análisis es "la presentación de los antecedentes y de todo material tangencial que permita al lector llegar a sus propias conclusiones, una vez en poder de los elementos de juicio necesarios". Valoración sería "la explicación personal y subjetiva de lo que una persona cree la noticia significa". Como consecuencia, análisis sería una explicación objetiva basada en el conocimiento a fondo de una situación y la valoración sería un juicio subjetivo.

Lo cierto es que la absoluta impersonalidad del relato, señala Fagoaga, es un objetivo inalcanzable tanto cuando se analiza como cuando se valora. Pese a que el análisis pueda ser presentado con la máxima objetividad posible, hay siempre una valoración implícita. Porque la valoración está implícita en la lógica

15 GRIJELMO, Álex: Op. cit., p. 119.

16 MARTÍNEZ ALBERTOS, José Luis: Op. cit., p. 206.

17 CHARNLEY, Michell V.: Op. cit., p.436. 
El análisis: ¿un género periodístico?

de datos explicativos (análisis) que no es más que el resultado de haber partido de un determinado background.

A modo de síntesis, Concha Fagoaga afirma que el análisis y la valoración deben servir para explicar los hechos y estimar consecuencias. El lenguaje propio de aquél que apela debe reducirse a usos editorialistas, usos legítimos en las columnas de opinión e inadecuados cuando sólo se trata de que los mensajes sean menos herméticos y los hechos salgan a la luz y dejen de estar ocultos.

Mientras que el análisis planteado en los mensajes interpretativos se basa en la explicación de los hechos y ahí se mantiene su sustrato esencial, los mensajes propios del periodismo de opinión analizan los hechos con el único propósito de ofrecer juicios morales y, en definitiva, de analizar las opiniones públicas.

\section{La estructura del análisis}

El análisis es un género periodístico interpretativo que nace en la prensa escrita y que prácticamente se instala en ella sin extenderse a otros medios como la radio o la televisión. La interpretación, en todo caso, siempre ha buscado en el periódico el soporte idóneo, mientras que los medios audiovisuales han optado por la inmediatez de la noticia. Así ha ocurrido también, al menos por el momento, con los diarios digitales. Randall se ha detenido en este aspecto: "El enfoque interpretativo resulta más necesario para los lectores en unos tiempos en que suelen enterarse de los hechos en primer lugar a través de la televisión y la radio. Además de profundizar en la actualidad más de lo que pueden hacerlo las emisoras de radio y televisión, los periódicos también deberían explicar el significado de los hechos y su evolución"18.

Pero el análisis informativo también es un género propio de las agencias de noticias. Aunque es cierto que las agencias transmiten fundamentalmente información, la tendencia es general en todas en aumentar el porcentaje de informaciones con firma, lo que implica un nivel más profundo de información, en cuanto a crónicas o análisis. Es el periodismo interpretativo o de explicación, afirma Rivas Troitiño, cuyos géneros esenciales son la panorámica, el análisis y la crónica. La agencia Efe define el análisis informativo, que lleva siempre firma, como aquel texto periodístico que debe centrarse en la interpretación o análisis, más que en la valoración, por lo que no debe incluir opiniones subjetivas. Su autor debe limitarse a presentar todos los elementos, los antecedentes y la documentación adecuada, para que el lector pueda formar su propia opinión o componer las predicciones que correspondan. Siempre debe estar fundado en fuentes u observaciones del corresponsal que deben ser citadas o apoyadas en opiniones o comentarios de expertos. 
Sirve también para resaltar informaciones de calidad escritas por expertos o por alguien relevante en el asunto al que se refieren ${ }^{19}$.

De cualquier manera, el análisis tiene o puede tener autonomía plena cuando, lejos de los juicios de valor, se limita a interpretar un acontecimiento de actualidad basándose en un background seleccionado previamente. Luisa Santamaría, respecto al análisis como género autónomo, ha escrito: «Esta nueva modalidad es quizá una de las formas periodísticas donde más fácilmente puede darse la ambigüedad entre los géneros de opinión y de información. Hoy está muy generalizado científicamente el convencimiento de que muchos de estos análisis tienen una indudable repercusión de carácter político. Sin embargo, algunos medios de comunicación poco escrupulosos con las normas deontológicas del trabajo periodístico -de las que, como es sabido, es fundamental la separación entre la información y la opinión- utilizan de manera poco ortodoxa textos periodísticos denominados análisis, prestándose a la confusión sistemática entre el dato y el juicio de valor».

Éste es, desde luego, uno de los graves riesgos que corre todo periodista cuando se enfrenta a la redacción del análisis como género periodístico. Porque ¿cómo se escribe un análisis? Inútiles los esquemas piramidales para este tipo de mensaje, el análisis adopta la forma del artículo periodístico, pero cualquier deducción debe apoyarse en el análisis y en un amplio background. El análisis parte de un lid, pero éste no es informativo, sino interpretativo, a fin de llevar al lector a poder analizar la noticia ya desde el primer párrafo. Éste no aporta acontecimientos inéditos, sino que hace mención a hechos de actualidad ya publicados. La interpretación ya debe aparecer resumida en el título del relato, queda justificada en el lid y se desarrolla a lo largo del cuerpo del relato en el que se va haciendo referencia a los hechos de actualidad, al background y al análisis, de manera que todos estos elementos «aparecen en la construcción de párrafos, de forma que la estructura del mensaje utiliza esos elementos en el orden lógico que tiende a reforzar y dar sentido a la interpretación inicial dada en el lead», añade Fagoaga.

Grijelmo sugiere que, antes de comenzar a escribir un análisis, conviene escoger un hilo conductor, una hipótesis que desarrollaremos a lo largo del texto. La documentación, es decir los datos antecedentes y datos de contexto, constituye parte esencial del análisis. Incluso la documentación, advierte este autor, debe acudir inmediatamente en socorro de cualquiera de las interpretaciones que se hayan escrito, y todavía más si se trata de la que reflejemos en el primer párrafo: "Cuando escribimos un análisis, cualquier visión subjetiva debe razonarse de inmediato. Se trata de decirle al lector: sobre este tema, yo entreveo tales signi-

19 RIVAS TROITIÑO, José Manuel: "Géneros periodísticos en las agencias de prensa", en Estudios sobre el mensaje periodístico, $\mathrm{n}^{\circ} .5,1999$, Servicio de Publicaciones Universidad Complutense de Madrid, p. 166. 
El análisis: ¿un género periodístico?

ficados, y las razones son éstas". Al contrario que un editorial, el análisis no tiene por qué establecer una interpretación unívoca, añade este periodista. Incluso el lector agradecerá que se planteen alternativas a la hipótesis principal, para que él tenga la oportunidad de identificarse con alguna de ellas por sí solo $^{20}$.

El análisis, en cualquier caso, es un género especializado, que ayuda al lector a desentrañar hechos a toro pasado. Por esta razón, se hace necesario desde el primer párrafo, como diría Bastenier, buscar una percha de actualidad, como se dice en la jerga periodística, es decir, relacionar nuestro análisis con el hecho de actualidad que vamos a diseccionar, aunque también se pueden elaborar análisis sobre sucesos alejados en el tiempo. A partir del primer párrafo, el autor dedicará los siguientes al desarrollo argumentativo amparado en el background y a abrir perspectivas a partir de la situación interpretada. Este autor entiende que el esfuerzo del periodista debe encaminarse a construir una teoría de lo sucedido. Por esta razón nos encontraremos más ante un discurso que ante una narración, de manera que "si el relato periodístico se puede decir que aspira a fijar una historia, un desarrollo de acontecimientos con protagonistas y escenario, el análisis sostiene un discurso explicativo directo, no deducido o derivado, como puede ocurrir con la crónica, donde la mera asociación de hechos puede producir interpretaciones, sino entrando a matar" 21 .

El análisis debe contener también en su estructura un cierre. En la última parte del texto, Bastenier propone que se pueda constituir un bloque que podríamos llamar de perspectiva, de lo que puede ocurrir. Y en el párrafo final se impone un cierre climático, una conclusión de fuerza, una propuesta para el futuro. Amparándose en un análisis de Manuel Azcárate, propone una posible estructura de análisis que contendría estas partes: 1) Propuesta; 2) Argumentación; 3) Perspectiva; 4) Solución (si ha lugar); y 5) Cierre, que puede ser futurible ${ }^{22}$.

El análisis es como el negativo fotográfico de la crónica, ha escrito Grijelmo. Si en ésta se mezclan, dice, información e interpretación, pero con predominio de la información, en el análisis sucede al contrario: predomina la interpretación, y la información queda en un segundo plano. Si en la crónica la información es en realidad la noticia, en el análisis la información son los antecedentes o documentación. Si en la crónica la interpretación debe formar parte de la sintaxis informativa, en el análisis cabe perfectamente que la información forme parte de la frase interpretativa. ${ }^{23}$ Grijelmo diferencia también el editorial del análisis, pues éste último ha de excluir también -como la crónica- los juicios de valor. Otra diferen-

20 GRIJELMO, Álex: Op. cit., pp. 117-118.

21 BASTENIER, Miguel Ángel: El blanco móvil. Curso de periodismo, Ediciones El País, Madrid, 2001, p. 109.

22 Ibídem, p. 114.

23 GRIJELMO, Álex: Op. cit., p. 117. 
cia respecto del editorial consiste en que el análisis construye principalmente hipótesis, mientras que el editorial establece sobre todo tesis.

En definitiva, si hay un género puramente interpretativo, éste sería el análisis, pues la crónica interpreta la noticia pero también informa, y el editorial ya valora los hechos e insta al lector a que se posicione al respecto. El riesgo del análisis siempre será minimizar esa porción de opinión que tiñe todo análisis objetivo y que empieza por utilizar un estilo que, a la vez que argumenta e informa, no incurra en la arrebato emocional fácil ni en la valoración innecesaria. Fagoaga propone que, como todo mensaje destinado a un público genérico, los rasgos de concisión y claridad sigan siendo cualidades indispensables en el ordenamiento de los párrafos: «Estos rasgos no son normas del periodismo informativo directo exclusivamente, son condiciones de subsistencia del lenguaje periodístico, sea cual sea la forma en que se determine el mensaje, sea cual sea el tratamiento de la información. La diferencia podría establecerse en el uso de determinados modos lingüísticos que aparecen con la producción de análisis y producción de juicios que, resulta evidente, no aparecen en los mensajes directos» ${ }^{24}$.

Una última característica que Fagoaga suma al análisis es la del significado emocional de las palabras que Badura ${ }^{25}$ diferencia del simple significado descriptivo. También el libro de estilo de El Mundo, como ya señalábamos, advertía del uso indiscriminado de adjetivos. En definitiva, Fagoaga concluye: «Esta búsqueda del significado emocional más que la del significado descriptivo es la que suele plantearse el redactor o redactora en el tratamiento de la información interpretativa, desde el título del mensaje hasta el último párrafo del cuerpo del relato» ${ }^{26}$.

Miguel Ángel Bastenier señala que el grado de personalización del análisis es algo mayor que en otros géneros, como la crónica. Porque el análisis tiene como objetivo el verdadero desiderátum del periodismo: explicar por qué pasan las cosas que pasan. A fin de cuentas es el fin de todos los géneros periodísticos, con sus diferentes posibilidades expresivas, pero el análisis, dice, pretende el mismo objetivo, pero liberándose para ello de toda limitación técnica o de estilo, de forma que el autor pueda volcar todos sus conocimientos sobre la materia en el texto. Para Bastenier, como ya hemos explicado, las limitaciones del analista no están en el estilo, sino que son de otro orden, es decir, de contenido. El análisis aspira a explicar, no a juzgar. Por esta razón, no expresa opiniones, sino conclusiones. De esta manera, con el análisis se da un paso más en la personalización: "El autor se halla más presente en el texto, y como no tiene apenas peripecia informativa que relatar, habla más directamente al lector sin la pantalla intermedia que es la narración de los hechos"27.

24 FAGOAGA, Concha: Op. cit., p. 32.

25 BADURA, Bernhard: Sociología de la comunicación, Ariel, Barcelona, 1979, p. 43.

26 FAGOAGA, Concha: Op. cit., p. 33.

27 BASTENIER, Miguel Ángel: Op. cit., pp. 107-108. 
El análisis: ¿un género periodístico?

En términos parecidos se ha expresado Randall cuando afirma que el objetivo del análisis es transmitir nuevas interpretaciones e ideas, aportando una visión diferente sobre el significado de los hechos. Así, señala, el análisis debe formar parte de la cobertura informativa, de manera que con este texto se logre lo que Willi Gutman, un archivero de prensa que huyó de la Alemania hitleriana, denominó "hacerse una exclusiva mediante la interpretación"28.

Porque en el análisis el material con que trabajamos es más nuestro que en la crónica, como diría Bastenier, el género no se entendería sin firma, ni le bastaría una acreditación de responsabilidad del propio periódico. Pero este mismo autor no ve la necesidad del yo narrador, como en la crónica, aunque "no creo que deba darse una exclusión tajante del mismo", ya que el carácter de investigación de los hechos debería favorecer la tercera persona, pero también "puede darse el caso de que los argumentos que se aporten para llegar a las conclusiones correspondientes, hayan sido directamente vividos por el autor, en cuyo caso no hay razón para excluir terminantemente el yo". En estas circunstancias, Bastenier propone que sería incluso preferible esa primera persona que "ese horror contemporáneo que es" el que esto firma", "el autor de estas líneas", "el periodista", etcétera, que todos, sin embargo, hemos usado alguna vez" 29 .

Respecto al título del análisis, Álex Grijelmo ha escrito que no necesita de características especiales, y puede compartir los mismos criterios que el reportaje y la crónica. No obstante, también comparte muchas características propias con los géneros de opinión. Pero, en realidad, el título del análisis, en tanto que es un género interpretativo, no está encabezado por títulos tan creativos como los del reportaje. El análisis no debe ser opinativo, si bien en la práctica es muy difícil desgajar la interpretación de la opinión. Pero este principio lleva al género a que sus títulos tampoco sean opinativos, o al menos sean todo lo menos opinativo posible. Mucho menos aún, exhortativos, como ocurre con el editorial. De cualquier manera, resulta casi imposible desproveer al título del análisis de aspecto crítico.

El titular del análisis suele contener dos elementos: epígrafe y título propiamente dicho. Este tipo de mensaje suele ser presentado al lector diferenciándolo con algunos significantes visuales. Este significante visual es un epígrafe que utiliza la señal "Análisis", para diferenciarlo de otros textos periodísticos de opinión tales como el editorial o el artículo.

\section{Conclusiones}

A modo de conclusión, podemos considerar el análisis género periodístico autónomo, porque contiene las suficientes características propias para poder dife- 
renciarlo de otros textos limítrofes como la crónica, el editorial, el artículo o la columna. No obstante, uno de los graves peligros que corre el analista, tal como hemos señalado con anterioridad, es el peligro de perderse en juicios de valor en deterioro de encontrar en el dato su pilar argumentativo.

Si lográsemos este objetivo, el análisis sería en realidad el único texto interpretativo, junto al perfil, dentro de la teoría de los géneros periodísticos. Porque tanto la crónica como el reportaje serían relatos informativos o informativo-interpretativos, y aunque es cierto que algunos géneros de opinión contienen interpretación también añaden juicios de valor.

El lenguaje del análisis debe someterse a las características del estilo informativo, pero éste no debe ser impersonal como el de la información, sino, muy al contrario, el periodista puede enriquecerlo con figuras retóricas e incluso podría hacer uso de la primera persona, al igual que en la crónica, si los acontecimientos que se explican así lo demandan. Con el lenguaje y con la titulación se corre el mismo riesgo que con el contenido: que en el desarrollo del texto los juicios de valor echen al arcén las interpretaciones basadas en el background seleccionado previamente y que nos sirve a modo de materia informativa con la que trabajar.

El análisis no es una narración, sino un discurso. Parte de hechos de actualidad, pero no informa sobre ellos. Muy al contrario, son su justificación y su razón de ser, y con éstos se elabora un lid interpretativo que nos sirve para encabezar el texto. A partir de ahí elaboramos el cuerpo informativo apoyando nuestro análisis en el background que se cerrará con un último párrafo de conclusiones. La vida del análisis aún es breve y confusa, pero los diarios han apostado por este nuevo género periodístico que no tiene cabida aún en los medios audiovisuales. 